Article

\title{
The Uncapacitatied Dynamic Single-Level Lot-Sizing Problem under a Time-Varying Environment and an Exact Solution Approach
}

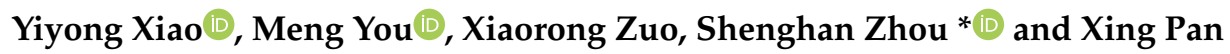 \\ School of Reliability and System Engineering, Beihang University, Beijing 100191, China; \\ xiaoyiyong@buaa.edu.cn (Y.X.); youmdyx@buaa.edu.cn (M.Y.); zuoxiaorong@buaa.edu.cn (X.Z.); \\ panxing@buaa.edu.cn (X.P.) \\ * Correspondence: zhoush@buaa.edu.cn; Tel.: +86-010-82316003
}

Received: 15 September 2018; Accepted: 22 October 2018; Published: 24 October 2018

check for updates

\begin{abstract}
The dynamic lot-sizing problem under a time-varying environment considers new features of the production system where factors such as production setup cost, unit inventory-holding cost, and unit price of manufacturing resources may vary in different periods over the whole planning horizon. Traditional lot-sizing theorems and algorithms are no longer fit for these situations as they had assumed constant environments. In our study, we investigated the dynamic lot-sizing problem with deteriorating production setup cost, a typical time-varying environment where the production setup is assumed to consume more preparing time and manufacturing resources as the production interval lasts longer. We proposed new lot-sizing models based on the traditional lot-sizing model considering the changing setup cost as a new constraint, called uncapacitatied dynamic single-level lot-sizing under a time-varying environment (UDSLLS-TVE for short). The UDSLLS-TVE problem has a more realistic significance and higher research value as it is closer to reality and has higher computational complexity as well. We proposed two mathematical programming models to describe UDSLLS_TVE with or without nonlinear components, respectively. Properties of the UDSLLS-TVE models were extensively analyzed and an exact algorithm based on forward dynamic programming (FDP) was proposed to solve this problem with a complexity of $\mathrm{O}\left(n^{2}\right)$. Comparative experiments with the commercial MIP solver CPLEX on synthesized problem instances showed that the FDP algorithm is a global optimization algorithm and has a high computational efficiency.
\end{abstract}

Keywords: lot-sizing problem; time-varying environment; deteriorating setup cost; dynamic programming; optimization

\section{Introduction}

The dynamic lot-sizing plan of a manufacturing system can be described as follows: In a given planning horizon $T$ with multiple production periods and different demands from customers, the production setup is determined within aperiodic periods over $T$, and the production sizes/quantities cover all the requirements of products (internal or external) in all periods with or without backlogging, in order to minimize the sum of production costs, setup costs, and inventory-holding costs occurred in the whole planning horizon [1,2]. The earlier studies of lot-sizing problems were originated from the cost reduction requirement from inventory management [3]. Since Harris [4] published the famous economic order quantity (EOQ) formula, which can be viewed as the earliest form of single-point lot-sizing optimization, the trade-off optimization between the purchase/setup cost and inventory-hold cost has become a hot research topic both in industries and academia. In terms of the classification principles by Karimi et al. [5], lot-sizing problems can be classified into different categories such 
as single or multi-level, capacitated or uncapacitated, dynamic or stationary, as shown in Table 1 as follows.

Table 1. General classification of lot-sizing problems.

\begin{tabular}{cc}
\hline Classification Principles & Categories \\
\hline Product structure & Single-level; Multi-level \\
Product number & Single-item; Multi-item \\
Production capacity & No capacity constraint; Capacity constraint \\
Product demand & Dynamic; Stationary \\
Production schedule length & Finite horizon; Infinite horizon \\
Existence of cost adjustment & No setup cost; Setup cost \\
Existence of stock shortage & No backlog; Backlog allowed \\
\hline
\end{tabular}

The dynamic single-level lot-sizing (DSLLS) problem is a basic form of many variants of the lot-sizing problem, referring to the case of taking into account time-varying demands of single product with only one level of product structure. In this situation, all intermediate processes of a product, from raw materials (or purchased semi-finished products) to the end-product, are assumed to be processed within a merged phase. Wagner and Whitin [2] first proposed a basic formulation of the DSLLS problem and an exact algorithm (i.e., the well-known WW algorithm) based dynamic programming. Mathematically, the basic formulation can be formulated as an optimization model as follows.

Minimize:

$$
T C=\sum_{t=1}^{n}\left(s_{t} \cdot y_{t}+h_{t} \cdot I_{t}\right)
$$

Subject to:

$$
\begin{array}{cc}
I_{t}=I_{t-1}+X_{t}-D_{t} & \forall t>1 \\
X_{t}-M \cdot y_{t} \leq 0 & \forall t \\
I_{t} \geq 0 & \forall t \\
X_{t} \geq 0 & \forall t
\end{array}
$$

In the above formulation, the objective function in Equation (1) is to minimize the sum of total production setup costs, $s_{t} \cdot y_{t}$, and inventory-holding costs, $h_{t} \cdot I_{t}$, of all periods in the whole planning horizon, where $n$ represents the number of periods, $t$ is the index of period, $h_{t}$ represents the unit inventory-holding cost at period $t, I_{t}$ represents the inventory level at the end of period $t, s_{t}$ represents the setup cost occurred in period $t$, and $y_{t}$ is binary decision variables indicating a production is setup in period $t$ (by $y_{t}=1$ ) or not (by $y_{t}=1$ ). Constraint $(2)$ is the inventory flow representing the balance of production quantity, demand and inventory, $X_{t}$ represents the production quantity in period $t$, and $D_{t}$ represents the external requirements. Constraint (3) indicates that the production quantity of each period cannot exceed the maximum capacity $M$ that can be a large number for uncapacitated capacity. Constraint (4) indicates that the stock shortage is not allowed. Constraint (5) indicates that the number of productions in each production period is nonnegative.

Wagner and Whitin [2] analyzed an important property of the model that in the $n$ production plan scope, any period $t(0<t<n)$ should satisfy the following conditions.

$$
\begin{array}{cl}
f_{t}\left(I_{t-1}\right)=\min \left[h \cdot I_{t-1}+s \cdot y_{t}+f_{t+1}\left(I_{t}+x_{t+1}-D_{t+1}\right)\right] & \forall t=1,2, \ldots, n-1 \\
f_{n}\left(I_{n-1}\right)=\min \left(h \cdot I_{n-1}+s \cdot y_{n}\right) & \forall t=n
\end{array}
$$


where $f_{t}$ represents the optimal total costs in the period $t$ and the Equations (6) and (7) represent the backward recursive equation based on dynamic programming. Based on these equations, Wagner and Whitin [2] put forward a famous WW algorithm for solving the dynamic single-level lot-sizing problem, based on the assumption that there are no capacity or resource limits in the production system. By using the backward dynamic programming, the single-level lot-sizing problem can be solved with exact solution efficiently. The WW algorithm can be represented by using the equation as follows:

$$
F(t)=\min \left[\begin{array}{c}
\min _{1 \leq j<t}\left[s_{j}+\sum_{p=j}^{t-1} \sum_{k=p+1}^{t} h_{p} D_{k}+F(j-1)\right] \\
s_{t}+F(t-1)
\end{array}\right]
$$

The WW algorithm is an exact algorithm which reduces the problem complexity of $\mathrm{O}\left(2^{n-1}\right)$ to a computation complexity of $n(n+1) / 2$. Several improved algorithms can be found in the literature [6-8]. Christophe et al. [6] proposed two polynomial time dynamic programming algorithms to solve the problem to optimality. Mathijn et al. [7] presented a Lagrangian heuristic to provide a feasible solution and lower bound for the problem. For costs and emissions such that the zero inventory property is satisfied, they gave a pseudo-polynomial algorithm, which can also be used to identify the complete set of Pareto optimal solutions of the bi-objective lot-sizing problem. Fanny [8] applied genetic programming (GP) to automatically generate specialized heuristics specific to the instance class. The contributions of these three papers are to reduce the computational complexity of the WW algorithm and save the calculation time. Lee et al. [9] studied the lot-sizing problem with time window and used the time window that can be adjusted by the user to ensure the demand in each period is being satisfied. For some early lot-sizing models, the demand for different periods is independent and can be considered as a constant. Macedo et al. [10] presents mixed-integer programming models to hybrid manufacturing and remanufacturing lot-sizing problems, in which remanufactured products are treated as new ones, so that both manufactured and remanufactured products compete to meet the demands. Sarakhsi et al. [11] studied the Joint Economic Lot-Sizing problem (JELS) for a single-vendor single-buyer system while demand is dependent on selling price. Rubasheuski et al. [12] considered the coordinated capacitated lot-sizing problem with stochastic non-stationary demand. Chowdhury et al. [13] presented a new $\mathrm{O}(\mathrm{T})$ algorithm for the dynamic single-item lot-sizing problem. Similar studies are also available [14-16].

The multi-level lot-sizing (MLLS) problem is an extension of DSLLS where the interdependencies of multiple items within an assembly structure are considered in the lot-size optimization [17]. Sahebjamnia and Torabi [18] developed a fuzzy stochastic multi-objective linear programming model for a multi-level, capacitated lot-sizing problem in a mixed assembly shop. Furlan and Santos [19] proposed a hybrid heuristic based on the bees algorithm combined with the fix-and-optimize heuristic to solve the multi-level capacitated lot-sizing problem. For large-sized problems, meta heuristics algorithms were reported to obtain the near-optimal solutions with good computational efficiencies, such as the Genetic Algorithm [20], the particle swarm optimization (PSO) algorithm [21], and Variable Neighborhood Search [22-25].

However, traditional lot-sizing theorems and algorithms were assumed for a constant production environment where the unit costs of manufacturing resources were stable in involved multiple periods. This assumption does not fit for some industries where their production environments are suffering from constantly changing in different periods. A time-varying environment can be considered as some production factors of the manufacturing system, such as the availability of manufacturing resources, material/labor costs/prices, production capacities, or cost of inventory-holding, are constantly changing during the planning horizon. A number of studies can be found in literature on the lot-sizing problems involving time-varying production factors such as time-varying demand [26], time-varying pricing [27], and time-varying cost [28]. Haase and Kimms [28] studied the capacitated lot-sizing problem where production setup cost depends on the order of production steps. Federgruen and 
Joern [27] designed a cost function that combined with the pricing model in time-varying demand and determined each lot-sizing quantity dynamically.

Other studies related to dynamic demand and inventory optimization in time-varying environments can be found in Dye et al. [29], Yang [3], Hong and Jern [30], Piperagkas et al. [31] and Tempelmeier and Hilger [32]. Dye et al. [29] proposed an approach for determining the optimal selling price with considering of the deterioration penalty of partial backlogging. Yang [3] and Balkhi [33] studied the lot-size inventory problem for deteriorating items considering partial backlogging. Hong and Jern [30] studied the dynamic lot-sizing and resource competition problem from the perspective of multiple firms and developed a capacity competition model. Piperagkas et al. [31] and Tempelmeier and Hilger [32] studied the dynamic lot-sizing problem with stochastic demands over the planning periods.

In this study, we investigated the uncapacitatied dynamic lot-sizing problem in a time-varying environment (UDSLLS-TVE) and proposed an exact forward dynamic programming algorithm. In UDSLLS_TVE, we considered a deteriorating production setup in the production system, assuming that the cost for production setup/initialization will increase higher if the production interval lasts longer. This is reasonable in discrete manufacturing systems because the longer the production interval is, the more difficult the production setup/initialization for preparing, machine inspection, cleaning, and heating will be, and thus more preparing time and manufacturing resources will be consumed in the production initialization/setup stage. We assumed that there is a positive correlation between the setup cost and the production interval. That means, if the production interval is increased one by one, the cost of production initialization will increase by a fixed rate. Existing algorithms such as the WW algorithm and its variants, is no longer suitable for solving the UDSLLS-TVE problem. We conducted a deep analysis of the properties of the UDSLLS-TVE model and proposed an exact algorithm based on forward dynamic programming for UDSLLS-TVE. Computational experiments were conducted to verify the feasibility and optimality of proposed models and algorithm.

The under investigated UDSLLS-TVE problem in this paper is toward the minimization of the manufacturing costs. Thus, our study can help to improve the sustainability of a factory's production system and is also helpful for the economic sustainability of a country's industry. The current research has achieved an initial success by considering several practical factors in a TVE. However, the influences of in-plant transport organization studied by Taniguchi and Shimamoto [34] and Gola and Kłosowski [35], and the capacity exploitation studied by Nikiforos [36] Kłosowski et al. [37] on manufacturing costs, have not been included yet in this paper, but will be considered in our future work.

The following contents of the paper are organized as follows. In Section 2, we provide the formal formulation of the UDSLLS-TVE problem, then discuss the properties of the proposed model. In Section 3, we propose a dynamic programming algorithm for UDSLLS-TVE problem, including algorithm analysis and algorithm implementation. In Section 4, computational experiments are conducted to verify the performances of the proposed model and algorithm. Finally, in Section 5, we summarize the paper and give further research directions.

\section{Problem Formulation}

\subsection{A Nonlinear Model of UDSLLS-TVE}

To model the UDSLLS-TVE with deteriorating production setup, we first define two new factors that are to be used in the problem formulation: (1) The production interval $L_{t}$, and (2) the growth rate of setup $\operatorname{cost} \alpha \in[0, \infty]$.

Definition 1. Production interval $L_{t}$ : It represents the number of unscheduled production periods between the period of $t$ and the latest period $t^{\prime}$ to arrange production during the limited planning cycle $n$. The value of $L_{t}$ ranges from $L_{t} \in[0, t-2](t \geq 2)$. 


$$
L_{t}= \begin{cases}t-1-\max \left\{t^{\prime} \cdot y_{t} \mid 1 \leq t^{\prime}<t\right\}, & \forall t \neq 1 \\ L_{0}, & \forall t=1\end{cases}
$$

In above definition, $y_{t}$ is a binary decision variable indicating whether the production is arranged during period $t$. If the production is arranged, then $y_{t}=1$, otherwise $y_{t}=0$. In Equation (9) $i$ is used to calculate the length of production interval $L_{t}$ for period $t$, indicating the number of periods that have no production setup before period $t$. When $t=1$, the production interval is initialized by the last period of previous planning cycle in accordance with the same rule. However, if only one planning cycle is considered, the production interval at the beginning period can be initialized as $L_{1}=0$. For other periods, we have $L_{t} \in[0, t-2]$. Note that the production interval $L_{t}$ will not be affected by whether a production setup is scheduled in period $t$ or not.

Definition 2. Growth rate of setup cost $\alpha$ : A fixed rate representing the unit increase in setup costs for every additional period of production interval. This rate is determined in advance according to the actual time-varying production environment.

By the above definition, the production setup cost can be considered as a deteriorating variable calculated as $s_{t}^{\prime}=s_{t}+\alpha \cdot L_{t}$. The new setup cost $s_{t}^{\prime}$ consists of two parts: (1) A fixed part of setup cost $s_{t}$ and (2) time-varying part determined by variable $L_{t}$.

Notations of parameters and decision variables used to describe the UDSLLS-TVE problem are summarized in advance in Table 2 as follows.

Table 2. Symbol definition of the uncapacitatied dynamic single-level lot-sizing under a time-varying environment (UDSLLS-TVE) model.

\begin{tabular}{cl}
\hline Symbol & \multicolumn{1}{c}{ Instructions } \\
\hline $\begin{array}{c}\text { Parameter: } \\
n\end{array}$ & Scope of the whole plan \\
$t$ & Planning period \\
$h_{t}$ & Holding costs of unit products at the end of period $t$ \\
$s_{t}$ & Setup cost during period $t$ \\
$D_{t}$ & External demand during period $t$ \\
$l$ & Leading time of production \\
$I_{0}$ & Initial inventory at the beginning of the planning horizon \\
$\alpha$ & Setup cost growth rate \\
Variables: & \\
$y_{t}$ & Binary decision variable indicating if a production is set up in period $t$ or not \\
$X_{t}$ & Non-negative decision variable indicating the production volume of lot-sizing in period $t$ \\
$I_{t}$ & Non-negative decision indicating the inventory level at the end of period $t$ \\
$L_{t}$ & Production interval \\
\hline
\end{tabular}

The UDSLLS-TVE problem is defined in a finite planning horizon with multiple production periods, in which time-varying demands from customers are known and must be met without backlogging. A nonlinear mathematical formulation of the UDSLLS-TVE problem is given as follows.

Minimize:

$$
\text { Total cost }=\sum_{t=1}^{n}\left(h_{t} \cdot I_{t}+s_{t} \cdot y_{t}+\alpha L_{t} y_{t}\right)
$$

Subject to:

$$
I_{t}= \begin{cases}I_{0}-D_{t} & \forall 1 \leq t<l \\ I_{t-1}+X_{t-l}-D_{t} & \forall l \leq t \leq n\end{cases}
$$




$$
\begin{array}{cc}
L_{t}=t-1-\max \left\{t^{\prime} \cdot y_{t^{\prime}} \mid 1 \leq t^{\prime}<t\right\} & \forall t \neq 1 \\
L_{1}=0 & \\
I_{t} \geq 0 & \forall t \\
X_{t} \geq 0 & \forall t \\
y_{t} \in\{0,1\} & \forall t
\end{array}
$$

The objective function in Equation (10) is to minimize the sum of the production setup cost and inventory-holding cost in all periods, including the deteriorating effect of the production interval on the setup costs. Constraint (11) is the inventory flow along the periods in the horizon. It represents the balance between production batches, external demands and inventory. Constraints (12) and (13) calculate the production interval $L_{t}$ for each period $t$ according to Definition 1 . The production interval of the first period is set to be 0 . Constraint (14) indicates that backlogging is not allowed. Constraint (15) indicates that the production quantity in each period is non-negative. Constraint (16) defines that $y_{t}$ is a binary decision variable, indicating that if a production setup is scheduled in period $t$, then, $y_{t}=1$; otherwise $y_{t}=0$.

The above UDSLLS-TVE model is nonlinear and has a higher level of complexity than traditional lot-sizing problems. In Section 3, we developed an exact solution approach based on forward dynamic programming with a computational complexity of $\mathrm{O}(n)$. In Section 2.1, we provided a linear model for the UDSLLS-TVE problem which can be optimally solved by commercial MIP solvers such as CPLEX and Lingo. In the following, we analyzed the new features of the above UDSLLS-TVE model and brought about new properties regarding the feasibility and optimality of the solution.

Property 1. For an optimal solution of the UDSLLS-TVE model formulated in Equations (10)-(16), it satisfies $I_{t} \cdot X_{t-l}=0$ and $I_{t} \cdot y_{t-l}=0$ at any period, $t$ and $t>l$, where $l$ is the leading time.

Proof. This proof is by contradiction. Assuming there is an optimal solution with a period, $t$ and $t>l$, that $I_{t} \cdot X_{t-l}=0$ holds. That means a production setup has been arranged at period $t-l$ for the demand in period $t$ (because the leading time is $l$ ) before the inventory being exhausted. We can always arrange the inventory quantity $I_{t-1}$ to be produced in period $t-l$. This leads to save the inventory-holding cost resulting from inventory $I_{t-l}$ and without changing the feasibility of the solution. Therefore, the newly arranged solution is better than the original optimal solution, which is contradictory to the assumption. Thus, the property $h_{t-1} \cdot I_{t-1} \geq 0$ holds. By a similar way, we can also prove that the property $I_{t} \cdot y_{t-l}=0$ holds.

Property 2. For an optimal solution of the UDSLLS-TVE model formulated in Equation (10)-(16), it satisfies $X_{t}=0$ or $\sum_{j=t+l}^{k} D_{j}$, where $k=\min \left\{t^{\prime} \mid t^{\prime} \geq t+l, y_{t^{\prime}}=1\right\}$ and $l$ is the leading time.

Proof. This property is straightforward as it is a common property of traditional lot-sizing models, indicating that the production lot-sizing is either zero or a positive number that covers all the demands in periods from $t+l$ to the next period that has been scheduled with a production setup. The introduction of deteriorating production setup cost does not change this general lot-sizing rule. 
Property 3. For an optimal solution of the UDSLLS-TVE model formulated in Equations (10)-(16), if the demand in the period $t^{*}$, i.e., $D_{t *}$, is satisfied by the production quantity in the period $t^{* *}$ and $t^{* *}<t^{*}$, i.e., $X_{t^{* *}}$, the demand $D_{t}$ for any period $t$ between $t^{* *}$ and $t^{*}-l$ is also satisfied by $X_{t^{* *}}$, where $l$ is the leading time.

Proof. The property is in accordance with the general first-in-first-out (FIFO) rule of lot-sizing problems, indicating that the demand in each period must be satisfied by the latest produced products. The FIFO rule guarantees the lowest inventory-holding cost for produced product and violation of this rule will always lead to a sub-optimal solution.

Property 4. For an optimal solution of the UDSLLS-TVE model formulated in Equations (10)-(16), if $D_{t}=0$ and $s_{t-l+1}-s_{t-l}-X_{t-l} \cdot h_{t-l}+\alpha<0$, then $y_{t-l}=0$ holds, where $t>l$ and $l$ is the leading time.

Proof. This is proven by contradiction. Assuming there is an optimal solution with a period, $t$ and $t>l$, that is contradictory to this property, i.e., $D_{t}=0, s_{t-l}>\alpha$, and $y_{t-l}=1$. We can always move the production setup in period $t-l$ to $t-l+1$ by letting $y_{t-l} \leftarrow 0$ and $y_{t-l+1} \leftarrow 1$, such that the new solution remains feasible (because of $D_{t}=0$ ) and the total cost change is $\Delta=s_{t-l+1}-s_{t-l}-$ $X_{t-l} \cdot h_{t-l}+\alpha$. As $\Delta<0$, thus the new solution is better than the original optimal solution, which is contradictory to the assumption.

\subsection{A Linear Model of UDSLLS-TVE}

To eliminate the nonlinear components introduced by the variable $L_{t}$ in the model formulated in Equations (10)-(16), which are in the objective function Equation (10) and Constraint (12), we use the unit increment of setup $u_{t}$, instead of $L_{t}$, to convert the nonlinear model into a linear one. The linear model will be used to serve as the benchmark method in the computational section to provide optimal solutions for comparing with the proposed exact dynamic programming algorithm.

Definition 3. Increment of setup cost $u_{t}$ : A binary decision variable indicating if one unit of setup cost occurred in period $t$ (by $\left.u_{t}=1\right)$ or not (by $\left.u_{t}=0\right)$.

The variable $u_{t}$, as an alternative of $L_{t}$, plays the same role in representing the deteriorating effect of the production interval on the setup costs. Thus, we can reformulate the UDSLLS-TVE problem as an integer linear programming model for as follows.

Minimize:

$$
\text { Total cost }=\sum_{t=1}^{n}\left(h_{t} \cdot I_{t}+s_{t} \cdot y_{t}+\alpha \cdot u_{t}\right)
$$

Subject to:

$$
\begin{array}{cl}
I_{t}= \begin{cases}I_{0}-D_{t} & \forall 1 \leq t<l \\
I_{t-1}+X_{t-l}-D_{t} & \forall l \leq t \leq n\end{cases} \\
u_{t} \geq u_{t+1}+y_{t+1}-2 \cdot y_{t} & \forall t<n \\
u_{n}=0 & \\
I_{t} \geq 0 & \forall t \\
X_{t} \geq 0 & \forall t \\
y_{t} \in\{0,1\} & \forall t
\end{array}
$$

Note that the objective function in Equation (17) allows us to set an individual increment of setup $\cos t \alpha_{t}$ for each period $t$, which enhances the model to fit for a more complex production environment. 
Constraints (19) and (20) are designed to guarantee that for each period $t$, an extra cost, $\alpha_{t}$, always occurs once there is no production setup in period $t$ (by $y_{t}=0$ ), and there is always no extra cost for the last period. The rest of the other constraints are the same with those in Section 2.1. Note that since the above model formulated in Equations (17)-(23) is a linear model, it can be optimally solved by the MIP solver CPLEX used in the experiments section for small-sized instances.

\section{Dynamic Programming Approach for UDSLLS-TVE Problem}

\subsection{Dynamic Programming Formulation}

Before giving the dynamic programming formulation for the UDSLLS-TVE problem, several new definitions that are to be used in the formulation are introduced in advance as follows.

Definition 4. Sub-problem $S_{t}$. It represents the UDSLLS-TVE sub-problem that covers only the first t periods (i.e., from period 1 to t) of the original problem $P$.

Definition 5. Optimal cost of $P_{t}$ at $y_{t}=1$ with respect to different $L_{t}: S_{t}\left(L_{t}\right)$. It represents the optimal total cost of sub-problem $P_{t}$, including production setup cost and inventory-holding cost, at the conditions that $y_{t}=1$ the production interval of period $t$ takes the value of $L_{t}$.

Definition 6. Optimal cost of $P_{t}$ at $y_{t}=1: f(t)$. It represents the optimal total cost of the sub-problem $P_{t}$ at the condition that a production setup is scheduled at period $t$, i.e., $y_{t}=1$.

Definition 7. Optimum production interval before period $t$ of $P_{t}$ at $y_{t}=1: L_{t}^{*}$. It indicates the optimal production interval before period t of problem $P_{t}$ if a production setup is scheduled in period $t$ (i.e., $y_{t}=1$ ). Under this situation, the problem $P_{t}$ has the cost of $f(t)$.

Without loss of generation and for the simplicity of the expression, we assumed a zero leading time in the formulation. According to the objective function (10) and Definition 5, the cost of sub-problem $P_{t}$ at $y_{t}=1$ can be formulated as a dynamic programming expressed as follows.

$$
S_{t}\left(L_{t}\right)= \begin{cases}S_{t-1}\left(L_{t-1}^{*}\right)+s_{t} & \forall L_{\mathrm{t}}=0 \\ S_{t-1-L_{t}}\left(L_{t-1-L_{t}}^{*}\right)+s_{t}+\alpha L_{t}+\sum_{j=t-1-L_{t}}^{t-2} \sum_{k=j+1}^{t-1} h_{j} D_{k} & \forall 1 \leq L_{t} \leq t-2\end{cases}
$$

The above Equation (24) is a forward recursion dynamic formulation for calculating the values of $S_{t}\left(L_{t}\right)$ from the first period to the last period. The term $\sum_{j=t-1}^{t-2} \sum_{-L_{t}}^{t-1} h_{k=j+1} D_{k}$ represents the inventory-holding cost occurred in the production intervals. According to Definition 6, $S_{t-1-L_{t}}\left(L_{t-1-L_{t}}^{*}\right)$ and $S_{t-1}\left(L_{t-1}^{*}\right)$ can be expressed as $f\left(t-1-L_{t}\right)$ and $f(t-1)$. Thus, the optimal cost of $P_{t}$ at $y_{t}=1$, i.e., $f(t)$, can be calculated with a forward dynamic programming expressed as follows.

$$
f(t)=\min \left\{\begin{array}{l}
\min _{1 \leq L_{t} \leq t-2}\left[\alpha L_{t}+s_{t}+\sum_{j=t-1-L_{t}}^{t-2} \sum_{k=j+1}^{t-1} h_{j} D_{k}+f\left(t-1-L_{t}\right)\right] \\
\alpha+s_{t}+f(t-1)
\end{array}\right\}
$$

Definition 8. Optimal Cost of $P_{t}$ at $y_{t}=0$ with respect to different $L_{t}: H_{t}\left(L_{t}\right)$. It represents the optimal total cost of sub-problem $P_{t}$, at the condition that $y_{t}=0$ and the production interval of period $t$ takes the value of $L_{t}$.

Definition 9. Optimal cost of $P_{t}$ at $y_{t}=0: g(t)$. It represents the optimal total cost of the sub-problem $P_{t}$ at the condition that a production setup is scheduled at period $t$, i.e., $y_{t}=0$. 
Definition 10. Optimum production interval before period t of $P_{t}$ at $y_{t}=0: L_{t}^{\prime}$. It indicates the optimal production interval before period t of problem $P_{t}$ if no production setup is scheduled in period $t$ (i.e., $y_{t}=0$ ). Under this situation, the problem $P_{t}$ has the cost of $g(t)$.

According to Definitions 5 and 8 , the cost of sub-problem $P_{t}$ at $y_{t}=0$ can be calculated by using the forwardly recursive formulation in Equation (26) as follows.

$$
H_{t}\left(L_{t}\right)=\sum_{j=t-1}^{t-1} \sum_{L_{t}}^{t} h_{k=j+1} D_{k}+H_{t-1-L_{t}}\left(L_{t-1-L_{t}}\right) \quad \forall t>1
$$

By above Equation (26), all values of $H_{t}\left(L_{t}\right)$ can be calculated with respect to each value of variable $L_{t}$ in $[0, t-2]$. Thus, according to Definition 10, the function $g(t)$, i.e., the optimal cost of $P_{t}$ at $y_{t}=0$, takes the minimum value among them.

$$
g(t)=\min _{0 \leq L_{t} \leq t-2}\left[\sum_{j=t-1-L_{t}}^{t-1} \sum_{k=j+1}^{t} h_{j} D_{k}+f\left(t-1-L_{t}\right)\right], \quad \forall t>1
$$

Let $F(t)$ represent the optimal cost of the sub-problem $P_{t}$. Thus, $F(t)$ is determined by comparing the lower value between $f(t)$ and $g(t)$ for the case of period $t$ being scheduled with a production setup (by $\left.y_{t}=1\right)$ or not $\left(\right.$ by $\left.y_{t}=0\right)$.

$$
F(t)= \begin{cases}s_{t} & \forall t=1 \\ \min [f(t), g(t)] & \forall 1<t \leq n\end{cases}
$$

Thus, the above Equations (25), (27) and (28) form a forward dynamic programming formulation, by which the optimal cost of sub-problem $P_{t}$ can be determined forwardly from $t=1$ to $t=n$, and finally the optimal cost of original problem $P_{n}$ is determined.

\subsection{Algorithm of Dynamic Programming}

Based on the formulation in Section 3.1 for the UDSLLS-TVE model, we assumed that for a problem instance with $n$ planning period, the dynamic programming algorithm for sub-problem $P_{t^{*}}$ at any period $t^{*}$ can be described by the steps as follows.

(1) Suppose that a production setup is scheduled in period $t^{* *}\left(t^{* *}=1,2, \ldots, t^{* *}-1\right)$, the production quantity covers the demand of $D_{t}$ for $t=t^{* *}, t^{* *}+1, \ldots, t^{*}-1$, and the production interval corresponding to period $t$ is $L_{t}=t^{*}-1, t^{*}-2, \ldots, 1$.

(2) Calculate $H_{t}\left(L_{t}\right)$ and $S_{t}\left(L_{t}\right)$ at the period $t^{*}$ and for $L_{t}=t^{*}-1, t^{*}-2, \ldots, 1$ according to Equations (24) and (26), respectively.

(3) Determine $f(t), g(t)$, and $F(t)$ at the period $t^{*}$ according to Equations (25), (27) and (28), respectively.

(4) If $t^{*}=n$, the algorithm ends; Otherwise, let $t^{*} \leftarrow t^{*}+1$ and repeat steps (1), (2), (3) and (4).

According to the above formulation, we just need to make a calculation of $2(t-1)$ times for the sub-problem $P_{t}$ at period $t$, and the optimal solution of the original problem can be obtained by no more than $n(n-1)$ times of calculation. Therefore, the algorithm has a polynomial computational complexity of $\mathrm{O}(n(n-1))$. The pseudo code of the algorithm is provided in Figure 1. 
(1) Let $t=1, y_{1}=1, L_{1}=0$, and $f(1)=S_{1}(0)=s_{1}$.

(2) For $t=2$ to $n$, find the optimal total cost $F(t)$ corresponding to period $t$, this includes two sub-steps of calculating the optimal production $\operatorname{cost} f(t)$ and the optimal non-production cost $g(t)$ during the period $t$.

(i) Calculate $f(t)$ for period $t$ :

(1) When $L_{t}=0, S_{t}(0)=\alpha+s_{t}+f(t-1)$;

(2)When $1 \leq L_{t} \leq t-2, S_{t}\left(L_{t}\right)=\alpha L_{t}+s_{t}+\sum_{j=t-1-L_{t}}^{t-2} \sum_{k=j+1}^{t-1} h_{j} D_{k}+f\left(t-1-L_{t}\right)$;

(3) Compare the values for each $S_{t}\left(L_{t}\right)$, the minimum value is $f(t)$ and the correspond $L_{t}$ is $L_{t}^{*}$.

(ii) Calculate $g(t)$ for period $t$ :

(1) When $0 \leq L_{t} \leq t-2, \quad H_{t}\left(L_{t}\right)=\sum_{j=t-1-L_{t}}^{t-1} \sum_{k=j+1}^{t} h_{j} D_{k}+H_{t-1-L_{t}}\left(L_{t-1-L_{t}}\right)$

(2) Compare the value for each $H\left(L_{t}\right)$, the minimum value is $g(t)$ and the $L_{t}$ is $L^{\prime} t$.

(ii) Compare $f(t)$ and $g(t)$, the smaller one is $F(t)$.

(3) If $t=n$ then go to Step (4); otherwise, let $t \leftarrow t+1$, repeat steps (2), (3), and (4).

(4) When $t=n$, the $F(n)$ obtained is the optimal total cost for the entire planning period.

Figure 1. Pseudocode description of dynamic programming for the UDSLLS-TVE problem.

\section{Computational Experiment}

\subsection{Example Verification of Dynamic Programming Algorithm}

First, we verified the feasibility of the algorithm in Figure 1 by comparing the results with that obtained by the classic WW algorithm. The problem instance is given in Table 3, and includes the external demand, setup cost, and unit holding cost for a planning horizon with 12 periods/months. The production lot-size for each month is randomly determined. The unit increment of production setup cost is set by $\alpha=50$. The leading time is zero.

Table 3. Algorithm description of the UDSLLS-TVE problem.

\begin{tabular}{ccccc}
\hline Month $(\boldsymbol{t})$ & $\boldsymbol{D}_{\boldsymbol{t}}$ & $\boldsymbol{s}_{\boldsymbol{t}}$ & $\boldsymbol{\alpha}$ & $\boldsymbol{h}_{\boldsymbol{t}}$ \\
\hline 1 & 69 & 85 & 50 & 1 \\
2 & 29 & 102 & 50 & 1 \\
3 & 36 & 102 & 50 & 1 \\
4 & 61 & 101 & 50 & 1 \\
5 & 61 & 98 & 50 & 1 \\
6 & 26 & 114 & 50 & 1 \\
7 & 34 & 105 & 50 & 1 \\
8 & 67 & 86 & 50 & 1 \\
9 & 45 & 119 & 50 & 1 \\
10 & 67 & 110 & 50 & 1 \\
11 & 79 & 98 & 50 & 1 \\
12 & 56 & 114 & 50 & 1 \\
AVG & 52.5 & 102.8 & 50 & 1 \\
\hline
\end{tabular}

The forward dynamic programming algorithm proposed in Section 3.2 was coded by VC++ 6.0 language executed in a PC computer with a Windows 7 system. The RAM size is 2 GB and CPU is Core i3 dual-core M380 (4 CPUs) $2.53 \mathrm{GHz}$. The problem instances were solved with optimal solution $F(12)=1091$. Detailed production schedules and the production lot-size in all planning periods are shown in Table 4. 
Table 4. Solution results of the UDSLLS-TVE case.

\begin{tabular}{ccccccccccccc}
\hline Planning Period & $\mathbf{1}$ & $\mathbf{2}$ & $\mathbf{3}$ & $\mathbf{4}$ & $\mathbf{5}$ & $\mathbf{6}$ & $\mathbf{7}$ & $\mathbf{8}$ & $\mathbf{9}$ & $\mathbf{1 0}$ & $\mathbf{1 1}$ & $\mathbf{1 2}$ \\
\hline$y_{t}$ & 1 & 0 & 1 & 1 & 1 & 0 & 1 & 1 & 0 & 1 & 1 & 0 \\
$X_{t}$ & 98 & 0 & 36 & 61 & 87 & 0 & 34 & 112 & 0 & 67 & 135 & 0 \\
\hline
\end{tabular}

In order to verify the optimality of the dynamic algorithm, we enumerated all combinations of feasible solutions and found that the optimal solution is the same with that found by the dynamic programming algorithm. In addition, the solution efficiency is greatly improved because the solution time is reduced from exponential time to polynomial time.

\subsection{Comparison through Large-Scale Experiments}

In order to better verify the dynamic programming algorithm proposed in this paper, large-scale calculation experiments were conducted. We randomly generated 100 problem instances with 12,24 , 48 planning periods, respectively. The forward dynamic programming algorithm was used to solve all these test problem instances. After that, we used commercial software AMPL/CPLEX (Version 12.0) to solve these problem instances with the linear UDSLLS-TVE model formulated in Equations (17)-(23). All tested instances were optimally solved by the AMPL/CPLEX software. In Tables 5-7, we show the first five instances of the tested 100 instances by two methods.

Table 5. Results of problem instances with 12 periods.

\begin{tabular}{ccccc}
\hline \multirow{2}{*}{ No. } & \multicolumn{2}{c}{ Dynamic Programming } & & AMPL/CPLEX \\
\cline { 2 - 3 } \cline { 5 - 5 } & Cost & Time & & Cost \\
\hline 1 & 769.93 & $<1 \mathrm{~s}$ & & 769.93 \\
2 & 717.54 & $<1 \mathrm{~s}$ & & 717.54 \\
3 & 510.17 & $<1 \mathrm{~s}$ & & 510.17 \\
4 & 566.52 & $<1 \mathrm{~s}$ & & 566.52 \\
5 & 720.04 & $<1 \mathrm{~s}$ & $\ldots$ & 720.04 \\
$\ldots$ & $\ldots$ & $<1 \mathrm{~s}$ & $\ldots$ & $\ldots 12.37$ \\
\hline AVG of 100 & 712.37 & & & \\
\hline
\end{tabular}

Table 6. Results of problem instances with 24 periods.

\begin{tabular}{ccccc}
\hline \multirow{2}{*}{ No. } & \multicolumn{2}{c}{ Dynamic Programming } & & AMPL/CPLEX \\
\cline { 2 - 3 } \cline { 5 - 5 } & Cost & Time & & Cost \\
\hline 1 & 1373.02 & $<1 \mathrm{~s}$ & & 1373.02 \\
2 & 1588.75 & $<1 \mathrm{~s}$ & & 1588.75 \\
3 & 1412.26 & $<1 \mathrm{~s}$ & & 1412.26 \\
4 & 1103.34 & $<1 \mathrm{~s}$ & & 1103.34 \\
5 & 1450.20 & $<1 \mathrm{~s}$ & $\ldots$ & 1450.20 \\
$\ldots$ & $\ldots$ & $<1 \mathrm{~s}$ & $\ldots$ & $\ldots$ \\
AVG of 100 & 1482.06 & & & 1482.06 \\
\hline
\end{tabular}

Table 7. Results of problem instances with 48 periods.

\begin{tabular}{ccccc}
\hline \multirow{2}{*}{ No. } & \multicolumn{2}{c}{ Dynamic Programming } & & AMPL/CPLEX \\
\cline { 2 - 3 } \cline { 5 - 5 } & Cost & Time & & Cost \\
\hline 1 & 2376.20 & $<1 \mathrm{~s}$ & & 2376.20 \\
2 & 2869.74 & $<1 \mathrm{~s}$ & & 2869.74 \\
3 & 3012.33 & $<1 \mathrm{~s}$ & & 3012.33 \\
4 & 2879.96 & $<1 \mathrm{~s}$ & & 2879.96 \\
5 & 2690.01 & $<1 \mathrm{~s}$ & $\ldots$ & 2690.01 \\
$\ldots$ & $\ldots$ & $<1 \mathrm{~s}$ & & $\ldots$ \\
AVG of 100 & 2793.16 & & & 2793.16 \\
\hline
\end{tabular}


In order to present the results of computer experiments to the readers more conveniently and intuitively, we listed the first five lines of the calculation results under 12, 24, 48 planning periods respectively and omit the rest. For different kinds of planning periods, we provided the average value of 100 problem instances by two different methods. From Tables 5-7, it can be observed that the dynamic programming algorithm obtained the same optimal solution obtained by the AMPL/XPLEX MIP solver. All tested instances were in perfect agreement with the optimal solution by the AMPL/CPLEX software. In addition, the computational complexity of AMPL algorithm is $2^{n}$ while that of dynamic programming algorithm is $n^{2}$. Computational time of AMPL/CPLEX increased more rapidly than that of the dynamic programming algorithm as the problem size increased. For all scales of problems tested in the experiments, the computational time spent by dynamic programming was always less than one second. That means the proposed model and approximation method are quite effective. The proposed models describe well the UDSLLS-TVE problem with mathematical formulations, and the proposed dynamic programming algorithm succeeds to yield optimal solutions of the UDSLLS-TVE model with high computational efficiencies.

\section{Conclusions}

The UDSLLS-TVE problem studied in this paper considered a continuous change of demands in different planning horizons and the changes of setup cost as well, and was formulated as mathematical programming models based the conventional lot-sizing model. We analyzed the influence of production interval on production setup cost in a time-varying environment. Two mathematical models were developed for the uncapacitated dynamic single-level lot-sizing problem under a time-varying environment (UDSLLS-TVE for short). Proposed properties of the UDSLLS-TVE problem were analyzed for developing efficient solution algorithms. An exact solution approach based on dynamic programming, which has a computational complexity of $\mathrm{O}\left(n^{2}\right)$, was developed for the UDSLLS-TVE problem and significantly reduced the complexity of original problem, which is $\mathrm{O}\left(2^{n}\right)$. Computational experiments were conducted to compare the obtained solution by our proposed algorithm with the optimal solution obtained by using AMPL/CPLEX software, which show the optimality and high efficiency of the dynamic programming algorithm. Though our study achieved a series of achievements mentioned above, the study was limited to machining process and did not take into account some other factors like in-plant transport organization and capacity exploitation. For future studies, multi-level product structures, in-plant transport organization, production capacity, and more time-varying variables can be taken into consideration to make the model more realistic.

Author Contributions: Conceptualization, Y.X.; Formal analysis, Y.X., M.Y. and S.Z.; Methodology, Y.X. and M.Y.; Supervision, X.Z., S.Z. and X.P.; Writing-original draft, M.Y.; Writing-review \& editing, Y.X., M.Y., X.Z., S.Z. and X.P.

Acknowledgments: This work is supported by the National Natural Science Foundation of China (Grant Nos. $71271009 \& 71501007 \& 71672006 \& 71871003)$. The study was also sponsored by the Aviation Science Foundation of China (2017ZG51081), the Technical Research Foundation (JSZL2016601A004) and the Graduate Student Education \& Development Foundation of Beihang University.

Conflicts of Interest: The authors declare no conflicts of interest.

\section{References}

1. Manne, A.S. Programming of Economic Lot Sizes. Manag. Sci. 1958, 4, 115-135. [CrossRef]

2. Wagner, H.M.; Whitin, T.M. Dynamic Version of the Economic Lot Size Model. Manag. Sci. 1958, 50, 1770-1774. [CrossRef]

3. Yang, H.L.A. Partial Backlogging Production-Inventory Lot-Size Model for Deteriorating Items with Time-Varying Production and Demand Rate over a Finite Time Horizon. Int. J. Syst. Sci. 2011, 42, 1397-1407. [CrossRef]

4. Harris, F.W. How Many Parts to Make at Once. Oper. Res. 1913, 38, 947-950. [CrossRef] 
5. Karimi, B.; Fatemi Ghomi, S.M.; Wilson, J.M. The Capacitated Lot Sizing Problem: A Review of Models and Algorithms. Omega 2003, 31, 365-378. [CrossRef]

6. Christophe, R.; Guillaume, G.; Ayse, A. Energy-Aware Lot Sizing Problem: Complexity Analysis and Exact Algorithms. Int. J. Prod. Econ. 2018, 203, 254-263.

7. Mathijn, J.H.; Raf, J.; Wilco, H.; Albert, P.M.W. The Economic Lot-Sizing Problem with an Emission Capacity Constraint. Eur. J. Oper. Res. 2015, 241, 50-62.

8. Fanny, H.; Christian, A.; Gonçalo, F.; Bernardo, A.L. Designing New Heuristics for the Capacitated Lot Sizing Problem by Genetic Programming. Comput. Oper. Res. 2018, 96, 1-14.

9. Lee, C.Y.; Cetinkaya, S.; Wagelmans, A.P. A Dynamic Lot Sizing Model with Demand Time Windows. Manag. Sci. 2001, 47, 1384-1395. [CrossRef]

10. Macedo, P.B.; Alem, D.; Santos, M.; Junior, M.L.; Moreno, A. Hybrid Manufacturing and Remanufacturing Lot-Sizing Problem with Stochastic Demand, Return, and Setup Costs. Int. J. Adv. Manuf. Technol. 2016, 82, 1241-1257. [CrossRef]

11. Sarakhsi, M.K.; Ghomi, S.M.T.F.; Karimi, B. Joint Economic Lot-Sizing Problem for a Two-Stage Supply Chain with Price-Sensitive Demand. Sci. Iran. 2016, 23, 1474-1487.

12. Rubasheuski, U.; Oppen, J.; Woodruff, D.L. A Stochastic Programming Approach to Solve a Coordinated Capacitated Stochastic Dynamic Demand Lot-Sizing Problem with Emergency Supplies. Int. J. Logist. Syst. Manag. 2018, 29, 173-189. [CrossRef]

13. Chowdhury, N.T.; Baki, M.F.; Azab, A. Dynamic Economic Lot-Sizing Problem: A New O(T) Algorithm for the Wagner-Whitin Model. Comput. Ind. Eng. 2018, 117, 6-18. [CrossRef]

14. Eduardo, C.; Pedro, A.; Qi, Z.; Bernardo, A.L. Adaptation and Approximate Strategies for Solving the Lot-Sizing and Scheduling Problem Under Multistage Demand Uncertainty. Int. J. Prod. Econ. 2018, 202, $81-96$.

15. Jauhari, W.A.; Laksono, P.W. A Joint Economic Lot-Sizing Problem with Fuzzy Demand, Defective Items and Environmental Impacts. Mater. Sci. Eng. 2017, 273, 12-18.

16. Gicquel, C.; Cheng, J. A Joint Chance-Constrained Programming Approach for the Single-Item Capacitated Lot-Sizing Problem with Stochastic Demand. Ann. Oper. Res. 2017, 4, 1-33. [CrossRef]

17. Almeder, C.; Klabjan, D.; Traxler, R.; Almada-Lobo, B. Lead Time Considerations for the Multi-Level Capacitated Lot-Sizing Problem. Eur. J. Oper. Res. 2015, 241, 727-738. [CrossRef]

18. Sahebjamnia, N.; Torabi, S.A. A Fuzzy Stochastic Programming Approach for Multi-Level Capacitated Lot-Sizing Problem under Uncertainty. Stud. Fuzz. Soft Comput. 2014, 317, 393-407.

19. Furlan, M.M.; Santos, M.O. BFO: A Hybrid Bees Algorithm for the Multi-Level Capacitated Lot-Sizing Problem. J. Intell. Manuf. 2017, 28, 1-16. [CrossRef]

20. Dellaert, N.; Jeunet, J. Solving Large Unconstrained Multilevel Lot-Sizing Problems Using a Hybrid Genetic Algorithm. Int. J. Prod. Res. 2000, 38, 1083-1099. [CrossRef]

21. Han, Y.; Tang, J.F.; Kaku, I.; Mu, L.F. Solving Uncapacitated Multilevel Lotsizing Problem Using a Particle Swarm Optimization with Flexible Inertial Weight. Comput. Math. Appl. 2009, 57, 1748-1755. [CrossRef]

22. Xiao, Y.; Zhang, R.; Kaku, I. A New Approach of Inventory Classification based on Loss Profit. Expert Syst. Appl. 2011, 38, 9382-9391. [CrossRef]

23. Xiao, Y.; Kaku, I.; Zhao, Q.; Zhang, R.A. Variable Neighborhood Search based Approach for Uncapacitated Multilevel Lot-Sizing Problems. Comput. Ind. Eng. 2011, 60, 218-227. [CrossRef]

24. Xiao, Y.; Kaku, I.; Zhao, Q.; Zhang, R. Neighborhood Search Techniques for Solving Uncapacitated Multilevel Lot-Sizing Problems. Comput. Oper. Res. 2012, 39, 647-658. [CrossRef]

25. Xiao, Y.; Zhang, R.; Zhao, Q.; Kaku, I.; Xu, Y. A Variable Neighborhood Search with an Effective Local Search for Uncapacitated Multilevel Lot-Sizing Problems. Eur. J. Oper. Res. 2014, 235, 102-114. [CrossRef]

26. Purohit, A.K.; Choudhary, D.; Shankar, R. Inventory Lot-Sizing with Supplier Selection under Non-Stationary Stochastic Demand. Int. Conf. Best Pract. Supply Chain Manag. 2015, 54, 2459-2469. [CrossRef]

27. Federgruen, A.; Joern, M. Competition under Time-Varying Demands and Dynamic lot Sizing Costs. Naval Res. Logist. 2009, 56, 57-73. [CrossRef]

28. Haase, K.; Kimms, A. Lot Sizing and Scheduling with Sequence-Dependent Setup Cost and Times and Efficient Rescheduling Opportunities. Int. J. Prod. Econ. 2000, 66, 159-169. [CrossRef]

29. Dye, C.Y.; Hsieh, T.P.; Ouyang, L.Y. Determining Optimal Selling Price and Lot Size with a Varying Rate of Deterioration and Exponential Partial Backlogging. Eur. J. Oper. Res. 2007, 181, 668-678. [CrossRef] 
30. Hong, Y.L.; Jern, M. Competition under Capacitated Dynamic Lot-Sizing with Capacity Acquisition. Int. J. Prod. Econ. 2011, 131, 535-544.

31. Piperagkas, G.S.; Konstantaras, I.; Skouri, K.; Parsopoulos, K.E. Solving the Stochastic Dynamic Lot-Sizing Problem through Nature-Inspired Heuristics. Comput. Oper. Res. 2012, 39, 1555-1565. [CrossRef]

32. Tempelmeier, H.; Hilger, T. Linear Programming Models for a Stochastic Dynamic Capacitated Lot Sizing Problem. Comput. Oper. Res. 2015, 59, 119-125. [CrossRef]

33. Balkhi, Z.T. On a Finite Horizon Production Lot Size Inventory Model for Deteriorating Items: An Optimal Solution. Eur. J. Oper. Res. 2018, 132, 210-223. [CrossRef]

34. Taniguchi, E.; Shimamoto, H. Intelligent Transportation System Based Dynamic Vehicle Routing and Scheduling with Variable Travel Times. Transp. Res. C 2004, 12, 235-250. [CrossRef]

35. Gola, A.; Kłosowski, G. Application of Fuzzy Logic and Genetic Algorithms in Automated Works Transport Organization. Adv. Intell. Syst. Comput. 2018, 620, 29-36.

36. Nikiforos, M. The (Normal) Rate of Capacity Utilization at the Firm Level. Metroeconomica 2013, 64, 513-538. [CrossRef]

37. Kłosowski, G.; Gola, A.; Świć, A. Application of Fuzzy Logic Controller for Machine Load Balancing in Discrete Manufacturing System. Lect. Notes Comput. Sci. 2015, 9375, 256-263.

(c) 2018 by the authors. Licensee MDPI, Basel, Switzerland. This article is an open access article distributed under the terms and conditions of the Creative Commons Attribution (CC BY) license (http:/ / creativecommons.org/licenses/by/4.0/). 